\title{
Cytological Evaluation and Report on a Case of Cutaneous Mast Cell Tumour in a Dog
}

\author{
N. Shinu Balima ${ }^{1 *}$ and S. Vairamuthu ${ }^{2}$ \\ ${ }^{1}$ Eden's pet clinic and boarding kennel, Mogappair East, Chennai - 600 037, India \\ ${ }^{2}$ Department of Centralised Clinical Laboratory, \\ Madras Veterinary College, Chennai-600007, India \\ *Corresponding author
}

\section{A B S T R A C T}

\section{Keywords}

Dog, nodule, fine needle, mast cell

Article Info

Accepted:

15 February 2020

Available Online:

10 March 2020
A 6 year old male pug breed of dog was presented to Eden pets care with a history of bleeding from a nodule present on the skin. The owner also informed that it has started as a wart like structure on the skin which was soft and fluctuating which has remained in the same size for 2 years. Increase in size of the nodule was seen for past two weeks. Clinical examination of the pet showed a $0.7 \mathrm{~cm}$ diameter nodule on the skin on the cranial aspect of right forelimb at the time of presentation. No pain was evinced on palpation. Cytological evaluation of fine needle aspiration was suggestive of mast cell tumour. This article outlines the cytological findings and the treatment adopted in this case.

\section{Introduction}

Cutaneous masses or nodules can occur in dogs due to a multitude of underlying causes such as tumour, parasites, allergic conditions or cysts, infectious conditions, granulomatous and non-granulomatous (Scott, 2001 and Santoro et al., 2008).

Mast cell tumors (MCT) are the most common cutaneous tumour which is an important differential for cutaneous nodular lesions in dogs. They are frequently seen in the dermis and subcutaneous tissue and the occurrence in the skin of extremities is by 40 $\%$. Proper identification of the nodular lesion is important for a better treatment plan and to decide the prognosis of the case.

\section{Case history and observation}

A 6 year old, male, pug breed of dog weighing $9.8 \mathrm{~kg}$ was presented to Eden pets care, pet clinic and boarding kennels, Mogappair, Chennai with a history of ulceration and bleeding from a nodule present on the skin. The owner informed that the nodule was present for more than 2 years 
but has increased in size only for the past two weeks and has started bleeding suddenly, which has stopped by itself.

Physical examination of the dog showed an dark red ulcerated nodular mass of 0.5 to 0.7 $\mathrm{cm}$ in diameter on the cranial aspect of right forearm.

No other nodular lesions were observed on the skin. The pet was active and alert with no lymph node swelling nor any clinical signs of concern. A fine needle aspiration was done to find out the aetiology of the nodular lesion.

\section{Results and Discussion}

\section{Cytological evaluation}

Cytological evaluation of the aspirate showed the presence of neoplastic cells which were are spherical to oval and are well differentiated, the nuclei and cytoplasm are indistinguishable due to numerous dense purple to pink granules.

Some mast cells are stained pale blue because of heavy degree of granulation and lack of stain penetration in nucleus which was suggestive of mast cell tumour (Fig.1).

The pet was treated orally with prednisone at the dose rate of $2 \mathrm{mg} / \mathrm{kg}$ for a period of 14 days followed by a dose rate of $1 \mathrm{mg} / \mathrm{Kg}$ for the next 14 days. The pet was reviewed after the treatment duration. The nodule has considerably reduced in size compared to the time of initial presentation.

MCT is the most common form of cutaneous tumour, but involvement of viscera also has been reported. (Misdorp, 2004). Mast cell tumor (MCT) is the second most frequently diagnosed malignancy in dogs(Dobson et al., 2002). MCT represents $16 \%$ to $21 \%$ of all canine cutaneous neoplasms(Hauck, 2013). The development of MCT is related to genetic factors which describes the breed predisposition in development of the tumour.

Dogs of bulldog ancestry are predisposed to the development of MCT. McNeil et al., 2006 stated that MCT in pugs are relatively benign, despite the presence of multiple cutaneous tumours in most cases.

Cutaneous MCTs can arise from the malignantly transformed mast cells of dermis or the subcutaneous connective tissue. Dermal tumors are usually well-defined, raised masses which are often hairless and erythematous which may be ulcerated and/or pruritic (Hattendorf and Nielsen, 1967).

According to O'Keefe, 1990 patients with tumours that grow slowly and remain localized for long periods have a better prognosis, whereas rapid or infiltrative growth usually indicates a poor prognosis.

\section{Diagnosis by FNAC}

A diagnosis, preferably by fine-needle aspiration and cytologic (FNAC) evaluation, is especially important for locally invasive tumours such as MCT.

FNAC has confirmed the presence of cells which were suggestive of mast cell tumour. Diagnosis and staging of the tumour determines the nature of treatment to be followed in any dog that is presented with mastocytoma.

\section{Staging of the tumour}

Staging of the tumour is important in terms of treatment and prognosis. WHO Clinical Staging System for Canine Mast Cell Tumourswas used in this case (Table 1). 
Table.1 WHO Clinical Staging System for Canine Mast Cell Tumors

\begin{tabular}{|l|l|}
\hline Stage I & $\begin{array}{l}\text { One tumor confined to the dermis, without regional lymph node } \\
\text { involvement }\end{array}$ \\
\hline Stage II & \begin{tabular}{l} 
One tumor confined to the dermis, with regional lymph node involvement \\
\hline Stage III
\end{tabular} $\begin{array}{l}\text { Multiple dermal tumors or large infiltrating tumor with or without regional } \\
\text { lymph node involvement }\end{array}$ \\
\hline Stage IV & $\begin{array}{l}\text { Any tumor with distant metastasis, or recurrence with metastasis (including } \\
\text { blood or bone marrow involvement) }\end{array}$ \\
\hline
\end{tabular}

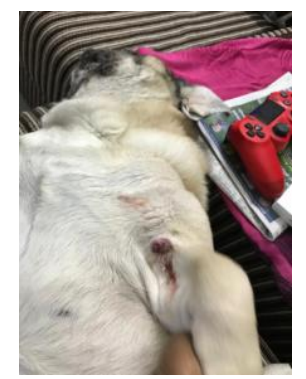

Fig.1 Ulcerated nodule on the cranial aspect of right forearm

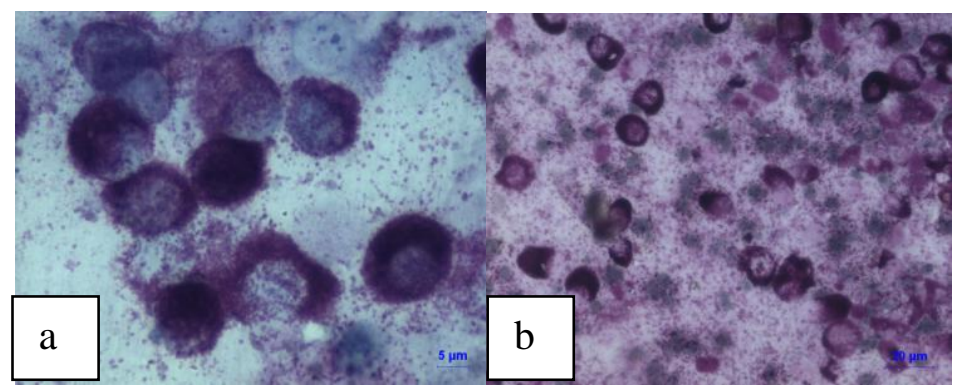

Fig.2 Cytology of mast cell tumour

Each stage is divided into (a) without systemic signs, and (b) with systemic signs

Although surgery remains the treatment of choice for localized MCT, considering a multimodality approach is important because recurrence after surgery was also seen (Northrup and Wall, 2005). Chemotherapy is primarily used for treatment of disseminated, nonresectable, or high-grade tumors, whereas radiation is the treatment of choice for microscopic residual disease.

\section{Clinical Management}

The presented case was assigned to stage I of MCT and Prednisone was chosen as drug for treatment, based on the effects of glucocorticoids being mentioned in the available literature. Corticosteroids have cytotoxic activity against MCTs (Takahashi et al., 1997), and treatment with these drugs is associated with limited adverse effects (Asboe, 1952). Glucocorticoids primarily affect fibroblasts and epithelial cells to reduce or inhibit the production of stem cell factor(Finotto et al., 1997).

At least three effects on MCT are attributed to glucocorticoids. First effect is seen in inhibition of production of growth factors and cytokines upon which newly generated cells are dependent (Pollack et al., 1991).Second, they act directly on mast cells to inhibit the 
normal pattern of granule formation. Third effect is attributed to the the antiinflammatory action of glucocorticoids which helps in decreasing the local edema, inflammation, and pruritus associated with the release of the cellular products (O'Keefe, 1990). Glucocorticoids canbe administered systemically or directly into the tumour but intraregional route can cause discomfort on injection, tumour sloughing, and iatrogenic hyperadrenocorticism.

Mccaw et al., 1994 has documented the effect of oral prednisone in cases on MCT with a 20 $\%$ positive response. Mcneil et al., 2006 concluded that MCT in pugs are relatively benign, despite the presence of multiple cutaneous tumours in most cases. Mast cell tumours manifest as a heterogenous disease, and individual treatment decisions must be based on the histologic grade of the tumour, clinical stage of disease, location of the mass, number of masses present, and concurrent clinical status of the patient. As it is difficult to predict the biologic behaviour of an individual tumour it is the decision of the veterinarian in deciding the best treatment in case of MCT in dogs.

\section{References}

Asboe-Hansen, G., 1952. Cortisone action. Proc Soc Exp Biol. 80: 677-679.

Dobson, J. M., S. Samuel, H. Milstein, K. Rogers and Wood J.L. 2002. Canine neoplasia in the UK: estimates of incidence rates from a population of insured dogs. J Small Anim Pract. 43(6):240-246.

Finotto, S., Y. A. Mekori and Metcalfe D. D. 1997. Glucocorticoids decrease tissue mast cell number by reducing the production of the c-kit ligand, stem cell factor, by resident cells: in vitro and in vivo evidence in murine systems. J Clin Invest. 99:17211728.
Hattendorf, G. H., and Nielsen, S. W. 1967. Pathologic survey of 300 extirpated canine mastocytomas. Zantralbl Veterinarmed 14:272-281.

Hauck, M. L., 2013. Tumors of the skin and subcutaneous tissues. In: Withrow SJ, Vail DM, Page RL, eds. Withrow and Macewen's Small Animal Clinical Oncology. 5th ed. Saunders, Philadelphia, pp. 305-320.

McCaw, D. L., M. A. Miller, G. K. Ogilvie, W. G. Brewer,M. K. Klien, F. W. Bell, and Anderson S. K. 1994. Response of canine mast cell tumors to treatment with oral prednisone at the dose rate of 1 milligram per kilogram body weight. J Vet Intern Med 8:406.

McNiel, E. A., A. L. Prink and O`Brien, T. D. 2006. Evaluation of risk and clinical outcome of mast cell tumours in pug dogs. In: Veterinary and Comparative Oncology.4 (1): 2-8.

Misdorp, W. 2004. Mast cells and canine mast cell tumors. A review. Vet Q. 26:156-169.

Northrup, N and Wall, M. 2005. Clinical management of mast cell tumors in dogs. Compend Contin Educ Pract Vet. 27:56-68.

O'Keefe, D. A. 1990. Canine Mast Cell Tumors Veterinary Clinics of North America: Small Animal Practice 20(4), 0195-5616/90.

Pollack, M. J., Flanders, J. A., and Johnson R. C. 1991. Disseminated malignant mastocytoma in a dog. J Am Aitim Hosp Assoc. 27:435.

Santoro, D., A. Spaterna, L. Mechelli and Ciaramella P. 2008. Cutaneous sterile pyogranuloma/granuloma syndrome in a dog. Can Vet J. 49:1204-1207.

Scott, D. W., W. J. Miller and Griffin G.E. 2001. Miscellaneous skin diseases. In: Muller and Kirk's, eds. Small Animal Dermatology, WB Saunders ,Philadelphia: 1136-1140.

Takahashi, T, T. Kadosawa, M. Nagase, M. Mochizuki, S. Matsunaga, R. Nishimura and Sasaki N. 1997. Inhibitory effects of glucocorticoids on proliferation of canine mast cell tumor. J Vet Med Sci. 59:9951001 . 


\section{How to cite this article:}

Shinu Balima. N and Vairamuthu. S. 2020. Cytological Evaluation and Report on a Case of Cutaneous Mast Cell Tumour in a Dog. Int.J.Curr.Microbiol.App.Sci. 9(03): 2180-2184. doi: https://doi.org/10.20546/ijcmas.2020.903.250 